two hospitalizations I was aware and appreciative of how care providers use verbal cues such as tone, inflection, as well as specific physical movements as tools to help communicate particular messages. What I did not really understand or appreciate until these two hospitalizations is the need to think about how the message being communicated will be, or could be, perceived - or misperceived-by the individual(s) receiving the message. Information sharing in medicine needs a contextual frame set by care providers to help patients and families calibrate their understanding of a message to the care provider's intent. I have no doubt that when I was told my daughter looked "pretty good" on her first day in the NICU that the message was intended to be positive. My understanding of "pretty good," though, was orientated to when she might be discharged. As I soon realized, the neonatologist likely meant she looked good relative to some other comparative measure but not that she was close to being discharged.

Second, I now fully appreciate the importance of consistency with respect to both the content and ways in which care providers inform patients or their families. It is frustrating for patients or their family members to hear one message from care providers and then hear what could be perceived as an opposite message from another provider-even when, in reality, the messages may not oppose each other. For example, during our first visit to the NICU with our son, the neonatologist told us that he "didn't look too bad." When he was discharged, however, a nurse congratulated us on our son leaving so quickly because "he was really struggling when he came in here [sic]." The messages from the neonatologist and this nurse do not contradict one another. Yet to my wife and me they conveyed two different meanings about his admission: the first painted his health in a semi-positive light, while the second painted his health in a negative light.

My two NICU experiences have also shaped how I perform clinical ethics consultations. Whenever I meet with a patient or the patient's surrogate for the first time, I try to avoid making any assumptions about the information sharing process, or about how much or how little information the patient or surrogate has or wants regarding the patient's health status. To make such assumptions is tantamount to paternalism. It should not be up to me or any other healthcare provider to decide for a patient or the patient's representatives when they receive information or the depth of information provided to them. When consulted and speaking with a patient or the patient's surrogate for the first time, I ask how much information they know about the situation, how much information they would like to know moving forward, and if there is a preference about how often or when updates are provided. To assist with my point about consistency in the message, I also attempt to make sure that when I speak with patients or their surrogates that one of the patient's physicians is present during the conversation. The practice of asking patients or their representatives to identify their preferences about informative communication between them and care providers is also something I incorporate into my teaching of medical students, residents, fellows, and staff.

There are other important ways my two NICU experiences have influenced my thinking about bioethics and how I perform clinical ethics consultations. However, the lessons I learned relating to the concept of information sharing are the most prevalent and common. My hope is that I continue to find new ways to use these two experiences as examples of the importance information sharing in medicine, and that these two experiences continue to help my development as a clinical ethicist and father.

\section{Fractured Humerous/ Fractured Humor-What a Broken Arm Taught Me About Racial and Cultural Privilege in Hospital Care}

Sara R. Jordan

S ome months after the incident, my husband would yell, in a fit of exasperated rage, "I'm leaving and you look less worried about 
my leaving than you looked when he broke his goddamned arm." My husband always hated my relationship with my training partner as he saw it for what it is-an intimate relationship with another man. The night Henry had his arm broken, as I tore out of my house, to which I had just returned, away from my husband to the side of my training partner, I realized just how much I had come to be torn between the two intimacies. Throughout the rest of the broken arm episode, I came to learn much more about the content of the corollary to intimacy - publicity, particularly of the universalist stripe.

It's been 20 months since Henry suffered a spiral fracture of the humerous, and while the arm is healed and no long lasting effects are visible except for a lengthy two-centimeter wide scar on his left arm, my perceptions of myself as a culturally sensitive ethicist are scarred as well.

\section{Training Partners as Intimate Partners}

Raymond Geuss says that an intimate relationship is one where we do things around that person that would provoke shame in us or reasonable disgust in others that were less intimate (2001, pp. 12-33). An athletic training partner is an intimate partner in ways that a sexual partner cannot be-the intimacy of training partners is acted out almost exclusively in a public space (e.g., gyms and race courses). Part of a long-term, committed, physically, psychologically, emotionally, financially, and publicly intimate relationship, training partners are those people who see our souls bare even if they never see us naked.

Henry was then, and is now again, my training partner par excellence. We run, lift weights, and paddle outrigger canoes together. We support each other often in the midst of competing mercilessly against one another. To me, he is sanctuary away from a difficult marriage and difficult job where I am a minority female working in a culture that I can never be part of, and a reminder that things can be fun, close and intimate in the middle of otherness. Against this background it is easy for even a casual observer to understand why, when a mutual friend called to say "I think Brad broke Henry's arm," I was terrified. Looking back, I was not terrified for him-how could this person who is seemingly built of calm and steady nerves be "broken" - but for me. "Oh my God, who am I going to train with?!"

Brad $(100+\mathrm{kg})$ and Henry $(75 \mathrm{~kg})$ decided to arm wrestle drunk, which all orthopaedic surgeons know is an unfortunate choice of activities as the force of contrary motion often results in a spiral fracture to the humerus. I returned to the bar where I had left them in a drunken, post-race melee, to find Henry a focused lump of clammy, grey skin. I cannot remember what we said to one another, if anything, people were shouting at me that an ambulance had been called, but I remember looking at his eyes, trying to get him to focus on me as he went into shock, and, to my own surprise, I still recall vividly drawing his head to my chest and kissing him on the forehead like I would with a wounded child. The feeling was maternal-as he wavered in consciousness waiting for the ambulance men to arrive-I would have done anything to trade places or to take the pain from him. An integral part of me was hurt and, hearkening to Gadamer's (1996) description of the intersubjective challenge presented by the indescribability of pain, I pained to know what he felt so that I could know how to alleviate it. Pushing each other, feeling the other's pain, and pushing one another through it is what training partners do for one another and at that moment, I wanted to perform my usual role.

The contrast between realizing that I am closer to my training partner than I originally supposed stood in juxtaposition against the realization that, while Henry was in the same teaching hospital in which I teach Responsible Conduct of Research, serve as a member of the institutional review board (IRB), and work closely with colleagues in the Medical Ethics unit, I am further away from my colleagues than I supposed.

\section{Cross-cultural Complexities}

Theorists of globalization like Thomas Friedman suppose that we are closer together due to global connections (2000). Others, like Pankaj Ghemawat suppose that closeness is all "globaloney" (2007). Throughout the three days of brief interactions 
with the hospital staff (e.g., nurses, physicians) during Henry's surgery and convalescence, I moved distinctly away from the idea of positive, shared ethics as Seyla Benhabib (2002) proposes, or the inclusiveness that Iris Marion Young supposes is the product of close, focused, communication (2000). Instead, I moved towards a Diogenean theory of cosmopolitical bioethics-if we care for people in the specific, or we take as important the cultural specificity of other persons, we come to resent their difference and seek to find sources of evidence that they should be shamed. To be truly universal, we must not care at all-we must be shameless (Geuss 2001, p. 27).

This story, told from the standpoint of almost anywhere else, would not have the cultural implications it does. What complicates this narrative is that it occurred in the complicated location of Hong Kong. Hong Kong, famed as a gateway to China for the West, is a place beset by continuously evolving, chaotic, fractal, narratives. Culturally, Hong Kong is always, at once, many competing things-sea and hills, farms and International Finance/ Commerce Centers. We, as part of a large expatriate community, live in two worlds populated by intense narrative complexity-the English and Chinese speaking, but western focused worlds of our careers, and the Chinese speaking, multi-cultural pastiche that is our athletic world. The Chinese speaking world was what arrived on the ambulance and pervaded the healthcare sphere. It was the appearance of these cultural others to help my friend that started me down the path of realization that provokes the major point of this article-cross cultural niceties and universal inclusion evaporate, even for those of us with the knowledge to know and do better, when an intimate partner's health and well-being are at risk.

Iris Young describes the idea of Inclusivenessgeneration of shared commitments through mutual struggle-as something that is generated through communication (2000, pp.52-80). When we cannot communicate sufficiently with one another-perhaps we don't speak the language enough to get beyond greeting - there is no open space for including one another. And, where there is no inclusion of others into our "moral community", there can be no trust (Uslaner 2002, p. 2). Instead, the product of stifled communication is mutual hesitation, frustration, and recrimination. If it is the case that one side obtains special privileges because of insufficient ability to co-communicate the other side will invariably feel negated, put upon, and taken advantage of. I am sure the ward staff felt taken advantage of, because we could not communicate well. I was able to repeatedly violate visiting hours rules and access multiple locations that I should not have been able to, inevitably due to my English speaking whiteness.

In my pre-event mind, taking advantage of cultural competencies or tendencies would have been wrong. To railroad "others" with whiteness or cultural privilege or occupational status would have been a repugnant act deserving of moral re-education. How could someone not see the demands of universal respect at play? My pre-theorization of this event would have insisted upon notes and tones of gratitude, of a commitment to cross-cultural cosmopolitical communicative action that traded experiences, expertise, and offers of professional assistance in a mutually comprehensible language. But, the experience of the event was all otherwise.

My universalist moral commitments were dashed by the lack of a universal language. That the ambulance men (and they are all men here) did not check blood pressure and oxygen saturation on a patient that was clearly in shock, but still took time for one to check his phone, rattled my professional courtesy. That the radiology technician did not speak sufficient English to explain the $x$-ray procedure to my friend irked me. That the Accident and Emergency ward nurses were more concerned his fee was paid before putting him in a more sufficient sling suggested a lack of genuine professional commitment to me. That, once Henry was admitted, the ward nurses allowed me in to the unit—a large, open plan, shared unit—very late in the evening struck me as immediately a violation of rules. That they did not explain to him or to me the visitation rules, because they could not, provoked a sense of moral outrage- what was the content of this assumption that expatriates did not come to 
teaching hospitals? I felt a tone of righteous anger when I overheard the nurses chatter to one another (in Cantonese) to ask who I was and whether his condition could be discussed with me. When they failed to grasp the concept "friend," they listed me as girlfriend and attempted to change the next of kin status on his chart. I found the ward nurses' heteronormative assumption of male + female $=$ sexual union to be evidence of low-learning. And, if they did not realize that heterosexuality is noncompulsory and that Eleatic love is a genuine possibility, could they possibly know how to properly change a dressing, or could they begin to know how to properly insert the proposed rods and screws that would paste Henry's arm back together? By the conclusion of the first evening, I was convinced that the hospital staff was incompetent. I had no clinical evidence of this-I never would have evidence of this, as they were fully competent and indeed excellent-but the lack of shared communicative capacity led me to this specious conclusion.

When Henry emerged from the hospital after three days, I was left with a lingering scar as well-could I consider myself to be an educated, culturally sensitive ethicist any longer, given that I had imagined incompetence of the "others" based upon the interactive effect of non-shared language and, by proxy, race?

\section{Post-Event Theorizing of the Role of Bioethicists in Cross-cultural Injury and Illness Management}

My experience with the injury of my training partner taught me that a love of cosmopolitan theories of ethics and bioethics do not equate to a cosmopolitical love applied equally to all. Under times of stress, like most humans, I sought the comforts of the familiar and resented the discomfort of the strange and the incomprehensible. I learned that my pretense towards enlightened theory ruptured under contrary torsional forces, like those experienced by arm wrestlers, and the resulting spiral fracture of my own academic self-image is still held together by screws and bars that I am thankful cannot be seen without $\mathrm{x}$-ray vision.
In the months following this event, as Henry convalesced and rehabilitated in his physical way, I turned to the problem of theorizing my experience. I had found that shared communicative capacity mattered more than I could have imagined for my ability to trust professionals of a different linguistic group and race. Contrary to Anderson's theory of "imagined communities" of shared professional norms and language, I found that ordinary questions-where are blankets?-mattered more than professional communicative capacity-what type of post-surgical pain management do you propose? As I pondered at greater length my feelings of distrust followed by shame for that distrust, I stopped to consider whether there is a role for clinical bioethicists as cross-cultural navigators.

The bioethicists' role, which I envision as distilling powerful emotive and analytic arguments for good and evil and placing those like salve onto complex medical situations, maps easily onto the role of a cross-cultural navigator. A navigator, or an individual trained to cross murky, rough, waters by reading the epiphenomenal signs of weather, constellations, and winds are those individuals that shepherd individuals across in times of distress. Without pausing to evoke the many images of the powerful navigators between the realms of life and death, I contend that future bioethics training ought to have components in cross-cultural navigation and communication. Instead of further programmatic learning in statistical or survey methodologies, students should be encouraged to seek culturally immersive internships that teach language and culture. Such experiences could allow students to come away from their training with a deeper cultural understanding as an aspect of academic training, which allows them to assist family members in cross-cultural negotiation situations to know how to apply the reasoning, language, and other epiphenomenon of one culture to another. Dangerously, though, reflecting on the Diogenean spirit of cosmopolitics described above, the consequence of navigating a family through the cross-cultural waters might be to bring them to the side where they do not care for the differences of the staff but care only for their loved one's co-struggle 
with difference and illness. By being cosmopolitical, we may encourage others to be shamelessly particularistic.

\section{References}

Benhabib, S. 2002. The claims of culture: Equality and diversity in the global era. Princeton, NJ: Princeton University Press.

Friedman, T. 2000. The Lexus and the olive tree: Understanding globalization. New York, NY: Farrar, Straus and Giroux.

Gadamer, H-G. 1996. The enigma of health: The art of healing in a scientific age. Stanford, CA: Stanford University Press.

Geuss, R. 2001. Public goods, private goods. Princeton, NJ: Princeton University Press.

Ghemawat, P. 2007. Refining global strategy: Crossing borders in a world where differences still matter. Boston, MA Harvard Business School Publishing Corporation.

Uslaner, E. M. 2002. The Moral Foundations of Trust. Cambridge, MA: Cambridge University Press.

Young, I. M. 2000. Inclusion and democracy. New York, NY: Oxford University Press.

\section{A Personal Experience of Prenatal Testing for Down Syndrome*}

By Chris Kaposy

$\mathrm{T}$ his is the story of the prenatal diagnosis of my son, Aaron, who has Down syndrome. The events in this story happened during an important period in my education and development as a bioethicist. The decisions that my wife Jan and I made through the different stages of prenatal testing were influenced by what I had learned about disability as a bioethicist in training, and these experiences have shaped me as a practicing clinical ethicist.

\footnotetext{
* I owe thanks to my wife Jan for helping me remember the details of her pregnancy.
}

In 2006 I had completed my Ph.D. in philosophy with a dissertation on infanticide. This odd topic was hard to explain to non-philosophers, who were usually relieved to hear that I was opposed to killing babies. Much of my intellectual activity while writing this dissertation was devoted to coming up with arguments opposing Peter Singer's gratuitous use of disabilities like Down syndrome in illustrating that it is acceptable to kill infants. I had read quite a bit of literature on the quality of life of people living with disabilities, and the family lives of people who have children with disabilities. The evidence in both areas was quite different and more positive than the doom and gloom about disabilities that you find in Singer's books.

At the end of my Ph.D. in 2006 Jan gave birth to our daughter Elizabeth. Early on in the pregnancy, we had declined the offer of prenatal testing. Jan and I both thought that we could welcome a child with disabilities into our lives, so prenatal diagnosis would not change anything for us. Though both of us were (and are) prochoice, we would not have chosen to abort a fetus that tested positive for a disability. My feelings were greatly influenced by my doctoral research and what I had learned about cognitive disabilities while studying with my dissertation advisor Eva Feder Kittay, whose daughter Sesha has profound disabilities, and who has written eloquently about her family life with Sesha.

In 2008 Jan was pregnant again. It was a planned pregnancy. As we had done the first time around, Jan declined the offer of maternal serum screening in our early prenatal visits to the midwife. We were planning a home birth. Midwifery care was more readily available in other places in Canada, but in our province, midwives were just on the cusp of being granted hospital privileges.

Around the $19^{\text {th }}$ week of her pregnancy, Jan went for a routine ultrasound. I came along. The ultrasound was a step we took voluntarily, since we wanted to know about any major abnormalities that the ultrasound could reveal, and we wanted to have a look at the fetus and see the beating heart. Toward the end of the procedure, the technician excused herself and went to speak briefly with the radiologist. She did not explain why. Soon afterward we 